\title{
Interactive comment on "Exogenous phosphorus compounds interact with nitrogen availability to regulate dynamics of soil inorganic phosphorus fractions in a meadow steppe" by Heyong Liu et al.
}

Heyong Liu et al.

ruzhenwang@iae.ac.cn

Received and published: 18 August 2019

Please find our respose to Reviewer \#2 in the supplemental PDF file.

Please also note the supplement to this comment:

https://www.biogeosciences-discuss.net/bg-2019-173/bg-2019-173-AC2-

supplement.pdf 